SALES JÚNIOR, R; SENHOR, RF; MICHEREFF, SJ; MEDEIROS, EV. 2017. Influência da adubação verde no declínio de monosporascus em solo naturalmente infestado. Horticultura Brasileira 35: 135-140. DOI - http://dx.doi.org/10.1590/S0102-053620170121

\title{
Influência da adubação verde no declínio de monosporascus em solo naturalmente infestado
}

\author{
Rui Sales Júnior'; ${ }^{1}$ Rosemberg F Senhor ${ }^{2}$; Sami J Michereff'; Erika V Medeiros ${ }^{3}$ \\ ${ }^{1}$ Universidade Federal Rural do Semi-Árido (UFERSA), Mossoró-RN, Brasil; ruisales@ufersa.edu.br (autor para correspondência); ${ }^{2}$ Uni- \\ versidade Federal Rural de Pernambuco (UFRPE), Recife-PE, Brasil; berg_fit@hotmail.com, sami@depa.ufrpe.br; ${ }^{3}$ UniversidadeFederal \\ Rural de Pernambuco (UFRPE), Garanhuns-PE, Brasil; evmbio@gmail.com
}

\section{RESUMO}

A incorporação de materiais vegetais no solo pode exercer influência sobre as populações dos patógenos e/ou suas atividades patogênicas. Este trabalho objetivou avaliar o potencial da adubação verde na indução da supressividade ao declínio de monosporascus em solo naturalmente infestado por Monosporascus cannonballus. Foram realizados dois experimentos, um em casa de vegetação e outro em campo. No primeiro, foram comparados 13 tratamentos considerando diferentes combinações do melão pele de sapo e os adubos verdes (Crotalaria spectabilis, C. juncea, Canavalia ensiformis, Cajanus cajan, Dolichos lablab e Stilozobium aterrimum) em quatro ciclos de cultivo. Os maiores valores de severidade da doença foram detectados nos plantios intercalados de C. cajan ou C. spectabilis com meloeiro, e nos cultivos sucessivos de $C$. ensiformis com incorporação, e meloeiro sem incorporação. Os maiores níveis populacionais de $M$. cannonballus nos solos foram verificados nos cultivos sucessivos de meloeiro sem incorporação, D. lablab, e nos cultivos intercalados de C. ensiformis, S. aterrimum, C. cajan, C. juncea ou D. lablab com meloeiro. As menores densidades obtidas ao final do experimento de casa de vegetação foram nos solos submetidos à adubação verde sucessiva de C. spectabilis, C. cajan, C. ensiformis, C. juncea e S. aterrimum e no plantio intercalado de C. Juncea. Em campo, o tratamento mais eficiente na redução da severidade do declínio de monosporascus e que apresentou, numericamente, maior número de frutos comerciais de melão foi o tratamento com S. aterrimum.

Palavras-chave: Cucumis melo, declínio das ramas, adubos verdes, supressividade.

\begin{abstract}
Influence of green manure in the monosporascus vine decline in naturally infested soils

The incorporation of plant material in soil can influence the populations of pathogens and/or pathogenic activities. This work aimed to evaluate the potential of green manure in the induction of suppressiveness to monosporascus vine decline of melons in soil naturally infested with Monosporascus cannonballus. Two experiments were carried out, one in greenhouse and the other under field conditions. In the first one, 13 treatments were compared, considering different combinations of melon 'Piel de sapo' and green manure (Crotalaria spectabilis, C. juncea, Canavalia ensiformis, Cajanus cajan, Dolichos lablab and Stilozobium aterrimum) in four growing seasons. The highest values of severity (SVD) of monosporascus vine decline were detected in interspersed cultivation with $C$. cajan or $C$. spectabilis with melon, successive cultivation of C. ensiformis with incorporation and of melon without incorporation. The highest $M$. cannonballus population levels in soil were observed in successive cultivation of melon without incorporation, D. lablab with incorporation, and in merged cultivation of $C$. ensiformis, $S$. aterrimum, C. cajan, C. juncea or D. lablab with melon. The lowest ascospores densities obtained at the end of experiment were found in soils submitted to successive green manure of $C$. spectabilis, $C$. cajan, C. ensiformis, C. juncea and $S$. aterrimum, and in merged cultivation of $C$. juncea. In field, the $S$. aterrimum was the most effective treatment in reducing the vine decline severity and presented, numerically, the highest number of commercial fruits of melon.
\end{abstract}

Keywords: Cucumis melo, vine decline, green manure, suppressiveness.

(Recebido para publicação em 23 de junho de 2015; aceito em 5 de maio de 2016) (Received on June 23, 2015; accepted on May 5, 2016)

$\mathrm{O}$ meloeiro (Cucumis melo) é uma das olerícolas mais cultivadas no mundo, sendo utilizadas práticas culturais intensivas associadas ao monocultivo. Isso tem favorecido um aumento considerável no número e incidência de doenças radiculares (Bruton, 1998). Dentre essas se destaca o declínio de monosporascus por limitar a produção de melão em diversos países, principalmente nas regiões áridas e semiáridas do mundo (Senhor et al., 2009; Ben Salem et al., 2013). O fungo Monosporascus cannonballus é um dos principais agentes fitopatógenos responsáveis pelo declínio de ramas ou morte súbita no meloeiro (Beltrán et al., 2005).
Algumas estratégias de controle têm sido empregadas no controle de $M$. cannonballus, sendo estas: aplicação de agentes de controle biológico (Sales Júnior et al., 2007), uso de compostos químicos (Medeiros et al., 2006a), fungicidas (Guimarães et al., 2008; Pivonia et al., 2010), uso de produtos naturais (Viana et al., 2008) utilização de porta 
enxertos (Demartelaere et al., 2015). Todas essas medidas são pouco eficazes e ainda não muito bem estabelecidas no Brasil. Portanto, medidas alternativas para o manejo desta enfermidade são urgentes e necessárias.

A base para o sucesso em um programa de manejo de doenças radiculares é a integração eficiente das práticas de controle. Neste contexto, a utilização de práticas culturais tem destacada importância no manejo de doenças de plantas, uma vez que o controle cultural das doenças radiculares induz a supressividade do solo (Janvier et al., 2007). Tal indução é um aspecto fundamental a ser investigado no desenvolvimento de estratégias sustentáveis de manejo de doenças radiculares. Os mecanismos de supressividade do solo podem ser os mais variados e incluem fatores abióticos e bióticos, como textura e tipos de argila, níveis de macro e micronutrientes, relação $\mathrm{C} / \mathrm{N}$, condutividade elétrica e pH do solo, grau de compactação do solo, densidade, biomassa e atividade microbiana do solo (Stone et al., 2004; Sharma, 2006; Hasna et al., 2007).

A supressividade do solo pode ser induzida pela adubação verde que permite o aporte de matéria orgânica no solo e reciclagem de macro e micronutrientes, melhorando a fertilidade e aumentando a produção, por parte da planta, de substâncias com ação antagônica aos fitopatógenos (Stone et al., 2004), as quais podem exercer influência sobre as populações ou atividades dos patógenos no solo (Sharma, 2006). Esta ainda propicia melhorias nas condições físicas, químicas e biológicas do solo, podendo intensificar a atividade microbiana e a competição entre os micro-organismos (Barros et al., 2014), promover a lise de estruturas dos patógenos, além de favorecer o crescimento das culturas econômicas em sucessão. Todavia, alguns resíduos promovem o aumento da incidência de doenças, por prover o enriquecimento do substrato ou solo, aumentando a sobrevivência do patógeno (Grünwald et al., 2000).

Apesar da importância e da busca por estratégias de controle da doença inexistem estudos sobre a influência da adubação verde na supressividade de espécies de Monosporascus. Além disso, existem poucas informações sobre o desenvolvimento da doença em raízes sob condições de campo. Tais conhecimentos são fundamentais para o entendimento da epidemiologia da doença e serviriam de instrumento para implementação de estratégias de manejo da doença. Por isso, este trabalho teve como objetivo avaliar o potencial da utilização de adubos verdes na indução da supressividade ao declínio de monosporascus em solos naturalmente infestados por M. cannonballus, em casa de vegetação e campo.

\section{MATERIAL E MÉTODOS}

A avaliação da influência da adubação verde sobre a população de $M$. cannonballus e sobre a severidade do declínio de monosporascus foi avaliada em dois experimentos, sendo o primeiro conduzido em casa de vegetação, durante o período quente e seco, com temperatura ambiente variando de 24 a $43^{\circ} \mathrm{C}$ e umidade relativa do ar entre $50 \mathrm{e}$ $74 \%$, na Universidade Federal Rural do Semi-Árido, em Mossoró-RN. O segundo experimento foi realizado em condição de campo, no período que coincide com a estação chuvosa da região, com temperatura ambiente variando de 24 a $40^{\circ} \mathrm{C}$ e umidade relativa do ar entre 70 e 90\%, na fazenda Agrícola Famosa, em Icapuí-CE (4'51'25' S, 37² $21^{\circ} 00^{\prime}$ 'O, altitude $42 \mathrm{~m})$.

A identificação prévia de $M$. cannonballus foi realizada mediante análise microscópica dos peritécios apresentando um único ascósporo esférico de coloração negra por asca, medindo 25-44 mm de diâmetro (Pollack \& Uecker, 1974), encontrada nas raízes de meloeiro cultivadas nos solos utilizados nestes experimentos.

Influência da adubação verde na população de $M$. cannonballus em casa de vegetação

Foram comparados 13 tratamentos em solo naturalmente infestado com $M$. cannonballus considerando diferentes combinações de melão e adubos verdes em quatro ciclos de cultivo. As plantas cultivadas foram melão pele de sapo cultivar Sancho e os adubos verdes: crotalária (Crotalaria spectabilis), feijão- -de-porco (Canavalia ensiformis), feijão guandu-forrageiro (Cajanus cajan), lablab (Dolichos lablab) e mucuna-preta (Stilozobium aterrimum). O solo utilizado apresentou textura franco-arenosa, coletado no município de Icapuí-CE, com histórico anterior de ocorrência do declínio de monosporascus, com as seguintes características químicas $\mathrm{pH}$ (água $1: 2,5)=7,1 ; \mathrm{Ca}=4,15 \mathrm{cmol}_{\mathrm{c}} \mathrm{dm}^{3}$; $\mathrm{Mg}=1,1 \mathrm{cmol}_{\mathrm{c}} \mathrm{dm}^{3} ; \mathrm{Al}=0,0 \mathrm{cmol}_{\mathrm{c}} / \mathrm{dm}^{3}$; $(\mathrm{H}+\mathrm{Al})=4,68 ; \mathrm{P}=231,83 \mathrm{mg} / \mathrm{kg} ; \mathrm{K}=$ $0,75 \mathrm{cmol}_{\mathrm{c} /} \mathrm{dm}^{3} ; \mathrm{Na}=0,78 \mathrm{cmol}_{\mathrm{c} /} \mathrm{dm}^{3}$; $\mathrm{MO}=0,73 \mathrm{~g} / \mathrm{kg}$ (Embrapa, 2009). Não houve necessidade de correção do solo por calagem ou adubação.

Em todos os tratamentos, antes do plantio, as sementes de adubo verde e de melão foram desinfestadas em solução de $\mathrm{NaClO} 1,5 \%$ por dois minutos, lavadas em água corrente e colocadas para secar durante 45 minutos à temperatura ambiente $\left(25 \pm 2^{\circ} \mathrm{C}\right)$, em câmara asséptica. O plantio das espécies de adubo verde foi realizado em vasos plásticos com capacidade de $4 \mathrm{~kg}$, contendo solo naturalmente infestado com M. cannonballus. Foram plantadas 10 sementes de cada espécie de adubo verde, e 10 dias após o plantio foi realizado o desbaste e mantidas seis plantas por vaso. Nos três primeiros ciclos de cultivo, ao atingirem o estádio de plena floração $(>50 \%$ das plantas em florescimento), os adubos verdes foram picados e incorporados ao solo, deixando um intervalo mínimo de 15 dias entre a incorporação e um novo ciclo para a decomposição parcial dos restos culturais. O plantio do meloeiro foi efetuado por meio de mudas, nove dias após a semeadura. O delineamento experimental foi inteiramente casualizado, com quatro repetições, e cada repetição constituída por um vaso com quatro plantas de melão ou seis de adubo verde.

Aos 55 dias após o transplantio (DAT), as raízes de meloeiro foram avaliadas quanto à severidade do declínio de monosporascus, com o auxílio de uma escala de notas adaptada, onde: $0=$ raízes saudáveis sem lesões ou descolorações, $1=$ suave descoloração, $2=$ descoloração moderada e/ou com lesões, 3= maceração moderada, 4= maceração severa das raízes. $\mathrm{O}$ índice 
de severidade da doença (SVD) em cada vaso foi calculado conforme McKinney (1923), pela expressão: SVD $=[\Sigma$ (grau da escala $x$ freqüência)/(número total de unidades $x$ grau máximo da escala)] x 100 , utilizando-se os dados obtidos com a escala de notas.

No final do quarto ciclo de cultivo, foram coletadas amostras de solo de todos os tratamentos para quantificação de M. cannonballus à profundidade de $10 \mathrm{a}$ $20 \mathrm{~cm}$, zona de maior concentração de ascósporos de M. cannonballus (Mertely et al., 1993). As amostras de solo foram secas em ambiente coberto, em seguida peneiradas em malha de $2 \mathrm{~mm}$ para retirada de resíduos. De cada amostra de solo foram retiradas seis repetições de laboratório, das quais os ascósporos de M. cannonballus foram extraídos pelo método de flotação de sacarose, conforme Beltrán et al. (2005) e ajustado por Sales Júnior et al. (2006). Inicialmente, as amostras foram peneiradas em uma malha de $250 \mu \mathrm{m}$, eliminando-se as partículas retidas. Uma amostra de $20 \mathrm{~g}$ de solo peneirado foi colocada em 500 $\mathrm{mL}$ de água, agitada durante 5 minutos $\mathrm{e}$ depois passada por peneiras com malhas de 75 e $30 \mu \mathrm{m}$. As partículas retidas na malha de $30 \mu \mathrm{m}$ foram lavadas em água corrente e centrifugadas a $3000 \mathrm{rpm}$, durante 5 minutos. O sobrenadante foi descartado e as partículas foram dissolvidas em $40 \mathrm{~mL}$ de solução de sacarose a $50 \%$ e centrifugadas a $3000 \mathrm{rpm}$, durante 3 minutos por duas vezes. Em seguida, o sobrenadante foi passado por uma malha de $30 \mu \mathrm{m}$ e as partículas retidas distribuídas em placas de Petri com fundo milimetrado, procedendo-se à contagem dos ascósporos característicos M. cannonballus em um microscópio estereoscópico a 40x.

Os dados de SVD e os de densidade de ascósporos não atenderam aos pressupostos da análise de variância (normalidade da distribuição dos erros e homogeneidade das variâncias) verificados pelos testes de Lilliefors e Cochran. Foram então transformados pelas equações $(x+1)^{1 / 2}$ e $\log (x+1)$, respectivamente e submetidos à análise de variância. As médias de SVD e densidade de ascósporos foram comparadas pelo teste de Scott-Knott $(\mathrm{p}=0,05)$. Todas as análises estatísticas foram realizadas com o auxílio do programa SAEG 9.1 (UFV, 2007).

Influência da adubação verde na população de $M$. cannonballus em campo

Foram comparados três tratamentos, selecionados do experimento anterior e que apresentaram resultados satisfatórios, em solo naturalmente infestado com M. cannonballus, considerando as combinações de C. juncea, mucuna-preta ou área de pousio com melão. Foi cultivado o meloeiro do grupo cantaloupe americano cultivar Rafael. O solo utilizado apresentou textura franco-arenosa, com histórico anterior de ocorrência do declínio de monosporascus em meloeiro, e com as mesmas características químicas do solo do experimento anterior.

Em todos os tratamentos, antes do plantio, as sementes de adubo verde e de melão foram desinfestadas, conforme citado anteriormente. Em cada parcela de adubo verde foram plantadas 15 linhas de $1 \mathrm{~m}$ com espaçamento de 0,5 $\mathrm{m}$ entre linhas por $0,25 \mathrm{~m}$ entre plantas. Ao atingirem o estádio de plena floração ( $>50 \%$ das plantas em florescimento), os adubos verdes foram picados e incorporados ao solo, deixando um intervalo mínimo de 20 dias entre a incorporação e um novo ciclo para a decomposição parcial dos restos culturais.

O cultivo do meloeiro foi efetuado mediante transplantio de mudas com nove dias de plantio, em espaçamento de $2 \mathrm{~m}$ entre linhas por $40 \mathrm{~cm}$ entre plantas. Os tratos culturais adotados na cultura foram os procedimentos padrões da região.

O delineamento experimental utilizado foi em blocos casualizados, com quatro repetições, sendo cada repetição constituída por uma parcela de 15 linhas de $10 \mathrm{~m}$ cultivados com adubo verde no primeiro ciclo e 4 linhas de $10 \mathrm{~m}$ cultivados com meloeiro no ciclo seguinte.

Aos 60 DAT, foram avaliados o número de frutos comerciais (NFR) e a severidade do declínio de monosporascus (SVD) em cada parcela. As raízes foram avaliadas quanto $S V D$, com o auxílio de uma escala de notas, conforme citado anteriormente. O SVD em cada parcela foi calculado conforme McKinney (1923), utilizando-se os dados obtidos com a escala de notas. Para a avaliação do sistema radicular e do NFR foi delimitado um quadrilátero de $12 \mathrm{~m}^{2}$, com 16 plantas de meloeiro nas duas linhas centrais de cada parcela de plantio.

No início e final de cada ciclo de cultivo, foram coletadas amostras de solo de todos os tratamentos para quantificação de ascósporos de M. cannonballus. As amostras foram compostas por cinco amostras simples de $3 \mathrm{~kg}$, coletadas em ziguezague, numa profundidade de 10 a $20 \mathrm{~cm}$. As mesmas foram postas para secar em ambiente coberto, em seguida peneiradas em malha de $2 \mathrm{~mm}$ para retirada de resíduos. Os ascósporos de $M$. cannonballus foram extraídos pelo método de flotação de sacarose, conforme Beltrán et al. (2005) e modificado por Sales Júnior et al. (2006).

Os dados de SVD e os de populações de ascósporos não atenderam aos pressupostos da análise de variância (normalidade da distribuição dos erros e homogeneidade das variâncias) verificados pelos testes de Lilliefors \& Cochran. Foram então transformados pelas equações $(\mathrm{x}+1)^{1 / 2}$ e $\log (\mathrm{x}+1)$, respectivamente, e submetidos à análise de variância. As médias de SVD, NFR e densidade de ascósporos foram comparadas pelo teste DMS $(p=0,05)$. Todas as análises estatísticas foram realizadas com o auxílio do programa SAEG 9.1 (UFV, 2007).

\section{RESULTADOS E DISCUSSÃO}

Influência da adubação verde na população de $M$. cannonballus em casa de vegetação

Quando a severidade do declínio de monosporascus (SVD) foi avaliada nas plantas de meloeiro ao término do $4^{\circ}$ ciclo de cultivo em casa de vegetação, foram verificadas diferenças significativas $(p \leq 0,05)$ nos níveis de severidade entre os diferentes tratamentos. Os maiores valores de SVD foram constatados nos plantios intercalados de guandu-forrageiro $(85,93 \%)$ e $C$. spectabilis $(93,75 \%)$ com meloeiro, e nos cultivos sucessivos de meloeiro sem incorporação (100\%), e de feijão-de-porco $(89,06 \%)$, com incorporação 
nos $2^{\circ}$ e $3^{\circ}$ ciclos de cultivo. Os demais tratamentos apresentaram valores de SVD inferiores e não diferiram $(\mathrm{p} \leq 0,05)$ entre si (Tabela 1).

Uma possível explicação para a elevada SVD verificada nos cultivos de meloeiro intercalados com adubo verde seria o curto intervalo de tempo (15 dias) deixado entre a incorporação dos restos culturais e o início de um novo ciclo do meloeiro, uma vez que a taxa de decomposição destas espécies é lenta, por causa dos elevados teores de lignina e celulose, além da relação $\mathrm{C} / \mathrm{N}$ mais alta do seu material vegetal (Burle et al., 2006). Isso sugere que os compostos tóxicos liberados durante a decomposição dos adubos verdes no solo podem não ter causado ação antagônica sobre fitopatógenos habitantes do solo (Lazarovits, 2001; Burle et al., 2006; Sharma, 2006).

No manejo de doenças radiculares devem ser usados adubos verdes que reduzam a população dos patógenos no solo e melhorem as propriedades físicas, químicas e biológicas deste (Hasna et al., 2007). A eficiência de controle de patógenos radiculares está relacionada com o volume de matéria fresca incorporada ao solo e ao período de tempo que o material leva para se decompor. É importante ressaltar que uma das estratégias da indução da supressividade com a incorporação de adubos verdes é a de estimular as populações de antagonistas potenciais naturalmente existentes no solo (Stone et al., 2004), que pode não ter acontecido nesse sistema de plantio intercalado, bem como, no plantio sucessivo com lablab. Apesar de esta planta ser proveniente de clima tropical e subtropical, ela é sensível à deficiência hídrica, fator que possivelmente contribuíu para a baixa eficiência desta espécie na supressividade.

A diferença nos níveis de SVD indica a variabilidade do potencial de inóculo em diferentes condições de solo resultantes dos tratamentos com adubações verdes e outros tipos de sucessão de cultivos, a qual evidencia o efeito supressivo ou conducivo do solo (Huber \& Schneider, 1982). Além disso, a decomposição destes materiais no solo libera compostos tóxicos voláteis e não voláteis que podem exercer ação anta-

Tabela 1. Severidade do declínio de monosporascus em raízes de meloeiro e densidade de ascósporos de Monosporascus cannonballus em solo ao final do $4^{\circ}$ ciclo de cultivo, após serem submetidas à incorporação de diferentes adubos verdes (severity of the vine decline caused by Monosporascus in melon roots and density of ascospores of $M$. cannonballus in soil at the end of the $4^{\text {th }}$ crop cycle, after being subjected to the incorporation of different green manures). Mossoró, UFERSA, 2010.

\begin{tabular}{lcc}
\hline Tratamento $^{1}$ & Severidade $(\%)^{\mathbf{2}}$ & $\begin{array}{c}\text { Densidade populacional } \\
\text { (ascósporos/g solo) }^{\mathbf{3}}\end{array}$ \\
\hline ME-ME-ME-ME & $100,00 \mathrm{a}^{4}$ & $0,89 \mathrm{a}^{4}$ \\
ME-SA-SA-ME & $68,75 \mathrm{~b}$ & $0,34 \mathrm{~b}$ \\
ME-CC-CC-ME & $78,12 \mathrm{~b}$ & $0,44 \mathrm{~b}$ \\
ME-CS-CS-ME & $75,00 \mathrm{~b}$ & $0,48 \mathrm{~b}$ \\
ME-CJ-CJ-ME & $64,06 \mathrm{~b}$ & $0,36 \mathrm{~b}$ \\
ME-CE-CE-ME & $89,06 \mathrm{a}$ & $0,36 \mathrm{~b}$ \\
ME-DL-DL-ME & $67,18 \mathrm{~b}$ & $0,73 \mathrm{a}$ \\
SA-ME-SA-ME & $70,31 \mathrm{~b}$ & $1,05 \mathrm{a}$ \\
CC-ME-CC-ME & $85,93 \mathrm{a}$ & $0,87 \mathrm{a}$ \\
CS-ME-CS-ME & $93,75 \mathrm{a}$ & $0,54 \mathrm{~b}$ \\
CJ-ME-CJ-ME & $68,75 \mathrm{~b}$ & $0,67 \mathrm{a}$ \\
CE-ME-CE-ME & $54,68 \mathrm{~b}$ & $1,10 \mathrm{a}$ \\
DL-ME-DL-ME & $76,56 \mathrm{~b}$ & $0,69 \mathrm{a}$ \\
\hline CV (\%) & 14,1 & 33,7 \\
\hline
\end{tabular}

${ }^{1} \mathrm{ME}=$ Cucumis melo (melão) (melon); $\mathrm{SA}=$ Stilozobium aterrimum (mucuna-preta) (mucuna); $\mathrm{CC}=$ Cajanus cajan (guandu-forrageiro) (pigeonpea); $\mathrm{CS}=$ Crotalaria spectabilis (showy crotalaria); $\mathrm{CJ}=$ Crotalaria juncea ( (canavali) $\} ; \mathrm{DL}=$ Dolichos lablab (lablab). ${ }^{2}$ Dados originais transformados em $(\mathrm{x}+1)^{1 / 2}$ \{original data transformed into $\left.(\mathrm{x}+1)^{1 / 2}\right\} .{ }^{3}$ Dados originais transformados em $\log (\mathrm{x}+1)$ \{original data transformed into the $\log (\mathrm{x}+1)\} .{ }^{4}$ Médias de quatro repetições (average of four replications). Médias seguidas pela mesma letra em coluna não diferem estatisticamente pelo teste de Scott-Knott $(\mathrm{p}=0,05)$ \{means followed by the same letter in column do not differ statistically by Scott-Knott test $(\mathrm{p}=0.05)\}$.

gônica sobre fitopatógenos habitantes do solo (Sharma, 2006).

A densidade de ascósporos de $M$. cannonballus nos solos variou de 0,34 a 1,10 ascósporos/g de solo, sendo verificada diferença significativa nos níveis de ascósporos entre os tratamentos estudados (Tabela 1).

A redução do número de ascósporos no solo pode ser explicada pela germinação destes na rizosfera do meloeiro e subsequente infecção das raízes, ou pela ação dos compostos tóxicos liberados durante a decomposição dos adubos verdes no solo (Lazarovits, 2001; Sharma, 2006).

Os maiores níveis populacionais de M. cannonballus no solo foram verificados nos cultivos sucessivos do meloeiro sem incorporação $(0,89)$, no plantio sucessivo de lablab $(0,73)$, e nos cultivos intercalados de feijão-de-porco $(1,10)$, de mucuna-preta $(1,05)$, de guandu-forrageiro $(0,87)$, de $C$. juncea $(0,67)$ e de lablab $(0,69)$ (ascósporo/g de solo), com meloeiro, mediante incorporação da massa fresca dos adubos verdes ao término do $1^{\circ}$ e $3^{\circ}$ ciclos de cultivo. Variações na resposta do patógeno aos diferentes adubos verdes podem ser decorrentes do tipo de material vegetal incorporado ao solo e do seu nível de decomposição (Hasna et al., 2007).

As menores densidades populacionais $(\mathrm{p} \leq 0,05)$ foram constatadas nos solos submetidos à adubação verde sucessiva de $C$. spectabilis $(0,48)$ guandu-forrageiro $(0,44)$, feijão-de-porco $(0,36), C$. juncea $(0,36)$ e mucuna-preta $(0,34)$ e no plantio intercalado de $C$. juncea $(0,54)$ (ascósporo/g de solo). Essa redução na densidade de ascósporos pode ter sido obtida devido aos efeitos tóxicos da amônia e do ácido nítrico 
Tabela 2. Densidade populacional de M. cannonballus, severidade do declínio de monosporascus em raízes de meloeiro (SVD) e número de frutos comerciais de melão (NFR) ao final do ciclo de cultivo, após serem submetidas à incorporação de diferentes adubos verdes e área de pousio \{M. cannonballus population density, severity of vine decline caused by Monosporascus in melon roots (SVD) and number of marketable fruits of melon (NFR) at the end of the crop cycle, after incorporation of different green manure and fallow area . Mossoró, UFERSA, 2010.

\begin{tabular}{|c|c|c|c|c|c|c|}
\hline \multirow{2}{*}{ Tratamento $^{1}$} & \multicolumn{2}{|c|}{ Ciclo do adubo verde ${ }^{2}$} & \multicolumn{2}{|c|}{ Ciclo do melão $^{2}$} & \multirow{2}{*}{$\mathbf{S V D}^{3}$} & \multirow{2}{*}{ NFR } \\
\hline & $\mathbf{P i}$ & Pf & $\mathbf{P i}$ & Pf & & \\
\hline AP-ME & $1,41 a^{4}$ & $0,87 \mathrm{a}$ & $1,29 \mathrm{a}$ & $0,91 \mathrm{a}$ & $46,90 b^{4}$ & $32,25 \mathrm{a}^{4}$ \\
\hline CJ-ME & $1,75 \mathrm{a}$ & $0,98 \mathrm{a}$ & 0,93 a & $0,76 \mathrm{a}$ & $47,83 \mathrm{~b}$ & $30,25 \mathrm{a}$ \\
\hline SA-ME & $1,00 \mathrm{a}$ & $1,57 \mathrm{a}$ & $0,68 \mathrm{a}$ & $0,83 \mathrm{a}$ & $41,90 \mathrm{~b}$ & $34,25 \mathrm{a}$ \\
\hline $\mathrm{CJ}+\mathrm{SA}-\mathrm{ME}$ & $1,02 \mathrm{a}$ & $1,40 \mathrm{a}$ & $0,76 \mathrm{a}$ & $0,94 \mathrm{a}$ & 58,48 a & $16,25 \mathrm{~b}$ \\
\hline CV (\%) & 27,66 & 27,13 & 14,21 & 14,21 & 6,53 & 8,14 \\
\hline
\end{tabular}

${ }^{1} \mathrm{AP}=$ area de pousio (falow); $\mathrm{ME}=$ Cucumis melo (melão) (melon); $\mathrm{CJ}=$ Crotalaria juncea (sunn hemp); $\mathrm{SA}=$ Stilozobium aterrimum (mucunapreta) (mucuna). $\mathrm{Pi}=$ população inicial (initial population), $\mathrm{Pf}=$ população final (final population). ${ }^{2}$ Dados originais transformados em log $(\mathrm{x}+1)$ \{original data transformed into the $\log (\mathrm{x}+1)\} .{ }^{3}$ Dados originais transformados em $(\mathrm{x}+1)^{1 / 2}$ \{original data transformed into $(\mathrm{x}+1)^{1 / 2}$ \}. ${ }^{4}$ Médias de quatro repetições (average of four replications). Médias seguidas pela mesma letra em coluna não diferem estatisticamente pelo teste DMS $(\mathrm{p}=0,05)$ \{means followed by the same letter in column do not differ statistically by DMS test $(\mathrm{p}=0.05)\}$.

liberado durante a decomposição da leguminosa no solo (Lazarovits, 2001). Além disso, as leguminosas têm um sistema radicular pivotante e profundo, que contribuiu para maior absorção de água (Torres et al., 2005) e, possivelmente, pode ter reduzido a germinação dos ascósporos no solo.

As correlações entre SVD e a população de $M$. cannonballus ao final do $2^{\circ}$ e $4^{\circ}$ ciclos de cultivo não foram significativas. A ausência de correlações significativas entre a densidade populacional de $M$. cannonballus no solo e a severidade do declínio de monosporascus denota contradição ao constatado em estudos envolvendo a supressividade natural de solos a este fungo, pois a intensidade do declínio de monosporascus, o percentual de argila e o pH do solo estão correlacionados com a densidade de ascósporos de $M$. cannonballus no solo, porém este último fator apresentou correlação negativa (Boughalleb et al., 2010).

\section{Influência da adubação verde na população de $M$. cannonballus em campo}

Houve diferença significativa $(\mathrm{p} \leq 0,05)$ entre sistemas de cobertura do solo para os fatores estudados, ou seja, a prática da adubação verde com C. juncea com mucuna-preta (CJ+SA-ME) influenciaram nos níveis de SVD, apresentando maiores índices de SVD $(58,48)$ (Tabela 2). Os demais tratamentos não diferenciaram estatisticamente quanto à SVD, sendo o tratamento SA-ME (mucuna) o que apresentou, numericamente, menor severidade do declínio de monosporascus e maior NFR (Tabela 2).

Foram observados ascósporos de $M$. cannonballus no solo estudado, antes mesmo de ser instalado o experimento, na primeira coleta de solo, apresentando pontos de máximo de 1,75; 1,00 e 1,41 ascósporos/g de solo para as áreas com os adubos verdes $C$. juncea e mucuna-preta e de pousio, respectivamente.

Foi verificada uma leve redução dos ascósporos no solo, nos tratamentos que tiveram a sucessão de dois ciclos de adubos verdes entre o ciclo de meloeiro, embora não tenha diferido estatisticamente $(\mathrm{p} \leq 0,05)$ entre si (Tabela 2$)$. Aparentemente, as raízes de mucuna-preta e de $C$. juncea não influenciaram a germinação dos ascósporos de $M$. cannonballus, em campo. Este fato pode ser explicado pelo curto intervalo de tempo entre a incorporação dos restos culturais e um novo ciclo de cultivo do meloeiro (20 dias), tendo em vista a lenta taxa de decomposição das espécies de crotalária e da mucuna-preta. Segundo Burle et al. (2006), a decomposição dessas espécies é lenta, em solos de cerrado pode levar aproximadamente 60 dias. Sugerindo a existência de algum fator de inibição da ação dos compostos tóxicos voláteis e não voláteis liberados durante a decomposição dos adubos verdes no solo (Lazarovits, 2001; Sharma, 2006).
Soma-se a isto, o fato de que a elevada precipitação pluviométrica (900 $\mathrm{mm}$ ), acima da média na região (600 $\mathrm{mm}$ ), reduziu ainda mais a velocidade de decomposição dos resíduos culturais, principalmente de $C$. juncea que não tolera encharcamento (Burle et al., 2006).

A detecção de ascósporos de $M$. cannonballus no solo é comum, pois trata-se de uma espécie de fungo habitante do solo e com ampla distribuição mundial, principalmente, nas regiões áridas e semiáridas (Waugh, 2003; Andrade et al., 2005, Medeiros et al., 2006b; Boughalleb et al., 2010). Esses níveis populacionais são baixos quando comparados aos registrados em outros estudos em que a mesma metodologia de extração foi utilizada, uma vez que, a média da densidade populacional de ascósporos de $M$. cannonballus em áreas não cultivadas de Caatinga e cultivadas com fruteiras no Brasil e no exterior é superior a 2 ascósporos/g de solo (Mertely et al., 1993; Medeiros et al., 2006b; Boughalleb et al., 2010). Apesar da baixa densidade de ascósporos, este fato é bastante preocupante, pois $M$. cannoballus é um dos fungos mais agressivos associados às raízes do meloeiro (Beltrán et al., 2005), e o inóculo inicial deste fungo que constitui nos ascósporos (Waugh et al., 2003) se incorporam no solo e se multiplicam ao final do ciclo da cultura podendo permanecer no solo por vários anos. Além disso, estudos realizados nesta 
região evidenciaram a presença de $M$. cannonballus em 30\% das áreas apresentando colapso (Andrade et al., 2005).

Os resultados obtidos no presente trabalho são relevantes pelo fato de ser o primeiro relato no Brasil da utilização de adubação verde no controle do declínio de monosporascus. Ficou evidenciada nos resultados uma redução na densidade populacional de ascósporos de $M$. cannonballus, proveniente da possibilidade de que compostos tóxicos voláteis e não voláteis liberados durante a decomposição dos adubos verdes no solo podem estar influenciando a atividade supressiva a este fitopatógeno, o que veio a resultar numa menor severidade da doença. Em campo, o tratamento com mucuna-preta (SA-ME) foi o que mostrou ser mais eficiente na redução da severidade do declínio de Monosporascus e que apresentou, numericamente, maior número de frutos comerciais de melão.

\section{AGRADECIMENTOS}

Os autores agradecem ao CNPq pela concessão de recursos para a realização desse trabalho e pelas bolsas de produtividade de Rui Sales Júnior, Sami Jorge Michereff e Erika Valente de Medeiros.

\section{REFERÊNCIAS}

ANDRADE, DEGT; MICHEREFF, SJ; BIONDI, CM; NASCIMENTO, CWA; SALES JÚNIOR, R. 2005. Frequência de fungos associados ao colapso do meloeiro e relação com características físicas, químicas e microbiológicas dos solos. Summa Phytopathologica 31: 327-333.

BARROS, JA; MEDEIROS, EV; NOTARO, KA; MORAES, WS; SILVA, JM; NASCIMENTO, TACES; MOREIRA, KA. 2014. Different cover promote sandy soil suppressiveness to root rot disease of cassava caused by Fusarium solani. African Journal of Microbiology Research 8: 967-973.

BELTRÁN, R; VICENT, A; SALES JÚNIOR, R; GARCÍA-JIMÉNEZ, J; ARMENGOL, J. 2005. Population dynamics of Monosporascus cannonballus ascospores in marsh soils in eastern Spain. European Journal of Plant Pathology 113: 357-365.

BEN SALEM, I; CORREIA, KC; BOUGHALLEB, $\mathrm{N}$; MICHEREFF, SJ; LEÓN, M; ABADCAMPOS, P; GARCÍA-JIMÉNEZ, J; ARMENGOL, J. 2013. Monosporascus eutypoides, a cause of root rot and vine decline in Tunisia, and evidence that M. cannonballus and M. eutypoides are distinct species. Plant Disease 97: 737-743.

BOUGHALLEB, N; SALEM, IB; BELTRÁN, R; VICENT, A; SIERRA, AP; ABAD-CAMPOS, P; GARCÍA-JIMÉNEZ, J; ARMENGOL, J. 2010. Occurrence of Monosporascus cannonballus in watermelon fields in Tunisia and factors associated with ascospore density in soil. Journal of Phytopathology 3: 137-142.

BRUTON, BD. 1998. Soilborne diseases in cucurbitaceae: pathogen virulence and host resistance. In: MCCreight, J. (ed). Cucurbitaceae '98. Alexandria: International Society for Horticultural Science, p.143-166.

BURLE, ML; CARVALHO, AM; AMABILE, RF; PEREIRA, J. 2006. Caracterização das espécies de adubo verde. In: CARVALHO, AM; AMABILE, RF (eds) Cerrado: adubação verde. Planaltina: Embrapa Cerrado. p.71-142.

DEMARTELAERE, ACF; FREITAS, CDM; SOARES, EB; QUEIROZ, APO; SALES JÚNIOR, R. 2015. Seleção de genótipos de cucurbitáceas resistentes a Monosporascus cannonballus e compatibilidade de portaenxertos. Revista Caatinga 28: 13-18.

EMBRAPA. 2009. Manual de análises químicas de solos, plantas e fertilizantes. Brasília, DF. 627p. (Embrapa Informações Tecnológica).

GRÜNWALD, NJ; HU, S; VAN BRUGGEN, AHC. 2000. Short-term cover crop decomposition in organic and conventional soils: characterization of soil C, N, microbial and plant pathogen dynamics. European Journal of Plant Pathology 106: 37-50.

GUIMARÃES, IM; SALES JÚNIOR, R; SILVA, KJP; MICHEREFF, SJ; NOGUEIRA, DRS. 2008. Efeito de fluazinam no controle de Monosporascus cannonballus, agente causal do declínio de ramas em meloeiro. Revista Caatinga 21: 147-153.

HASNA, MK; MÅRTENSSON, A; PERSSON, P; RÄMERT, B. 2007. Use of compost to manage corky root disease in organic tomato production. Annals of Applied Biology 151: 381-390.

HUBER, DM; SCHNEIDER, RW. 1982. The description and occurrence of suppressive soils. In: SCHNEIDER, RW (ed). Suppressive soils and plant disease. St. Paul: The American Phytopathological Society. p.1-7.

JANVIER，C； VILLENEUVE，F; ALABOUVETTE, C; EDEL-HERMANN, V; MATEILLE, T; STEINBERG, C. 2007. Soil health through soil disease suppression: Which strategy from descriptors to indicators? Soil Biology \& Biochemistry 39: 1-23.

LAZAROVITS, G. 2001. Management of soil-borne plant pathogens with organic soil amendments: a disease control strategy salvaged from the past. Canadian Journal of Plant Pathology 23: 1-7.

MCKINNEY, HH. 1923. Influence of soil temperature and moisture on infection of wheat seedlings by Helminthosporium sativum. Journal of Agricultural Research 26: 195-218.

MEDEIROS, EV; SALES JÚNIOR, R; MICHEREFF, SJ. 2006a. Eficiência de fungicidas no controle "in vitro" de Monosporascus cannonballus. Revista
Caatinga 19: 360-368

MEDEIROS, EV; SALES JÚNIOR, R; MICHEREFF, SJ; BARBOSA, MR. 2006b. Quantificação de ascósporos de Monosporascus cannonballus em solos não cultivados de Caatinga e em áreas de cultivo de melão do Rio Grande do Norte e Ceará. Fitopatologia Brasileira 31: 500-504.

MERTELY, JC; MARTYN, RD; MILLER, M; BRUTON, BD. 1993. An expanded host range for the muskmelon pathogen Monosporascus cannonballus. Plant Disease 77: 667-673.

PIVONIA, S; GERSTL, Z; MADUEL, A; LEVITA, R; 2010. Management of Monosporascus cannonballus sudden wilt of melon by soil application of fungicides. European Journal Plant Pathology 128: 201-209.

POLLACK, FG; UECKER, FA. 1974. Monosporascus cannonballus an unusual ascomycete in cantaloupe roots. Mycologia 66: 346-349.

SALES JÚNIOR, R; BELTRÁN, R; MICHEREFF, SJ; ARMENGOL, J; GARCÍA-JIMÉNEZ, J; MEDEIROS, EV. 2006. Análisis de distintos tipos de azúcares en el método de extracción de ascosporas de Monosporascus cannonballus en suelo. Fitopatologia Brasileira 31: 185187.

SALES JÚNIOR, R; BELTRÁN, R; VICENT, A; ARMENGOL, J; GARCÍA-JIMÉNEZ, J; MEDEIROS, EV. 2007. Controle biológico de Monosporascus cannonballus com Chaetomium. Fitopatologia brasileira 32: 70-74.

SENHOR, RF; SOUZA, PA; ANDRADE NETO, RC; PINTO, AC; SOARES, SRF. 2009. Colapso do meloeiro associado a Monosporascus cannonballus. Revista Verde de Agroecologia e Desenvolvimento Sustentável 4: 6-14.

SHARMA, RD. 2006. Adubação verde no controle de fitonematóides. In: CARVALHO, AM; AMABILE, RF (eds). Cerrado: adubação verde. Planaltina: Embrapa Cerrado. p.237264.

STONE, AG; SCHEUERELL, SJ; DARBY, HM. 2004. Suppression of soilborne diseases in field agricultural systems: organic matter management, cover cropping, and other cultural practices. In: MAGDOFF, F; WEIL, RR (eds). Soil organic matter in sustainable agriculture. Boca Raton: CRC Press. p.132164.

TORRES, JLR; PEREIRA, MG; ANDRIOLI, I; POLIDORO, JC; FABIAN, AJ. 2005. Decomposição e liberação de nitrogênio de resíduos culturais de plantas de cobertura em um solo de cerrado. Revista Brasileira de Ciências do Solo 29: 609-618.

VIANA, MG; ALBUQUERQUE, CC; MEDEIROS, EV; VIANA, FA; SILVA, KMB. 2008. Avaliação do potencial fungicida de extratos etanólicos de Senna alata contra Monosporascus cannonballus. Ciência e Agrotecnologia 32: 1387-1393.

WAUGH, MM; KIM, DH; FERRIN, DM; STANGHELLINI, ME. 2003. Reproductive potential of Monosporascus cannonballus. Plant Disease 87: 45-50. 